\title{
Improving the efficiency of the Fukui trap as a capture tool for the invasive European green crab (Carcinus maenas) in Newfoundland, Canada
}

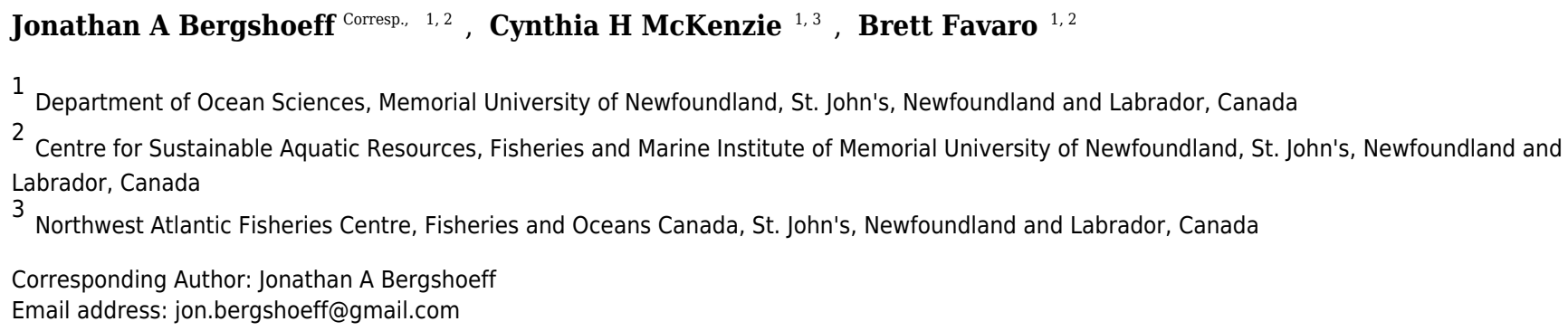

The European green crab (Carcinus maenas) is a crustacean species native to European and North African coastlines that has become one of the world's most successful marine invasive species. Targeted fishing programs aimed at removing green crabs from invaded ecosystems commonly use Fukui multi-species marine traps. Improving the efficiency of these traps would improve the ability to respond to green crab invasions. In this study, we developed four distinct trap modifications that were designed to facilitate the successful capture of green crabs, with the goal of improving the performance of the Fukui trap. We tested these modifications in situ during the summer of 2016 at two locations in Placentia Bay, Newfoundland. We discovered that three of our modified Fukui trap designs caught significantly more green crabs than the standard Fukui trap, increasing catch-per-uniteffort (CPUE) by as much as $81 \%$. We conclude that our top-performing modifications have great potential for widespread use with existing Fukui traps that are being used for green crab removal efforts. 
1 Improving the efficiency of the Fukui trap as a capture tool for the invasive

2 European green crab (Carcinus maenas) in Newfoundland, Canada

3 Jonathan A. Bergshoeff ${ }^{1,2}$, Cynthia H. McKenzie ${ }^{2,3}$, Brett Favaro ${ }^{1,2}$

$4 \quad{ }^{1}$ Centre for Sustainable Aquatic Resources, Fisheries and Marine Institute of Memorial

5 University of Newfoundland, St. John's, NL, Canada

$6 \quad{ }^{2}$ Department of Ocean Sciences, Memorial University of Newfoundland, St. John's, NL, Canada

$7{ }^{3}$ Northwest Atlantic Fisheries Centre, Fisheries and Oceans Canada, St. John's, NL, Canada

10 Corresponding Author:

11 Jonathan A. Bergshoeff

12 Email address: jon.bergshoeff@gmail.com

19 Word Count: 5,860 


\section{ABSTRACT}

The European green crab (Carcinus maenas) is a crustacean species native to European

22 and North African coastlines that has become one of the world's most successful marine invasive

23 species. Targeted fishing programs aimed at removing green crabs from invaded ecosystems

24 commonly use Fukui multi-species marine traps. Improving the efficiency of these traps would

25 improve the ability to respond to green crab invasions. In this study, we developed four distinct

26 trap modifications that were designed to facilitate the successful capture of green crabs, with the

27 goal of improving the performance of the Fukui trap. We tested these modifications in situ

28 during the summer of 2016 at two locations in Placentia Bay, Newfoundland. We discovered that

29 three of our modified Fukui trap designs caught significantly more green crabs than the standard

30 Fukui trap, increasing catch-per-unit-effort (CPUE) by as much as $81 \%$. We conclude that our

31 top-performing modifications have great potential for widespread use with existing Fukui traps

32 that are being used for green crab removal efforts. 


\section{Introduction}

The European green crab, Carcinus maenas (Linnaeus, 1758) is a globally successful aquatic invader, now present on every continent with temperate shores (Behrens Yamada, 2001; Roman, 2006; Darling et al., 2008). In Newfoundland, the European green crab (hereafter green crab) was first detected in 2007, and it has since become established across the southern and western coasts of the island (Best, McKenzie \& Couturier, 2017). These invasions threaten the native ecosystem through the destruction of sensitive eelgrass beds (Malyshev \& Quijón, 2011; Garbary et al., 2014; Matheson et al., 2016), predation on native bivalves (Ropes, 1968; Cohen, Carlton \& Fountain, 1995; Matheson \& McKenzie, 2014; Pickering et al., 2017; Poirier et al., 2017), and competition with native species for food and habitat (Cohen, Carlton \& Fountain, 1995; Rossong et al., 2006, 2012; Matheson \& Gagnon, 2012).

The complete eradication of an invasive species in a marine environment is virtually impossible once the organism has become established (Bax et al., 2003; Lodge et al., 2006), and may only be possible if the invasion is in a confined area and is addressed shortly after arrival (Culver \& M. Kuris, 2000; Simberloff, 2001; Bax et al., 2002). In Newfoundland, the complete eradication of green crabs is no longer considered an option. Therefore, removal efforts have focused on trapping to supress invasive populations, and to slow further spread (DFO, 2011a). Focused trapping has become the predominant strategy for addressing green crab invasions on both the east and west coasts of Canada (Duncombe \& Therriault, 2017; Bergshoeff et al., 2018).

These removal efforts usually use the Fukui multi-species marine trap (model FT-100, Fukui North America, Eganville, Ontario, Canada) to capture green crabs. These traps are favoured as they are light-weight, collapsible, durable, and can be deployed in large numbers from small boats or from shore. A standard Fukui trap consists of a rectangular, vinyl-coated 
56 high tensile steel frame $(60 \times 45 \times 20 \mathrm{~cm})$ covered with square, single-knotted, polyethylene

57 mesh (12 mm bar length). There are two entrances at either end of the trap, where two netting

58 panels form a horizontal "V" with a $45 \mathrm{~cm}$ expandable entry slit at the narrow end. To enter the

59 trap through either of these entrances, green crabs must force themselves through the entrance

60 which remains tightly compressed in its default position.

61 Our previous study was the first formal investigation of the interactions between green

62 crabs and the standard Fukui trap (Bergshoeff et al., 2018). In that study, we mounted

63 underwater video cameras to Fukui traps deployed in situ to assess the performance and

64 efficiency of this gear, and to identify design features that were inhibiting green crab entry or

65 facilitating exit prior to gear retrieval (Bergshoeff et al., 2017, 2018). Through these

66 experiments, we discovered that only $16 \%$ of the green crabs that attempted to enter the Fukui

67 trap were successfully captured. Our primary finding was that a combination of entanglement in

68 the mesh and the restrictive trap entrance would often inhibit the successful entry of green crabs

69 into the trap (Bergshoeff et al., 2018).

70 The main objective of this present study was to improve the performance of the Fukui

71 trap as a capture tool for green crabs. Based on our video observations from the previous

72 experiment, we developed four distinct modifications designed to facilitate the successful entry

73 of green crabs into Fukui traps. We tested these modified Fukui traps in situ during the summer

74 of 2016 and compared catch-per-unit-effort (CPUE) between each modified trap type and the

75 standard Fukui trap. Our modifications were designed to be simple and practical, so that they

76 could be easily applied to existing Fukui traps that are already in use for green crab removals.

77 Our primary goal was to assess how these novel modifications perform, and to determine their

78 potential for use in green crab removal programs that employ Fukui traps. 


\section{Methods}

\subsection{Modifications}

We developed four distinct trap modifications. For the first modification, we attached three $28.3 \mathrm{~g}(1-\mathrm{oz})$ lead bass casting sinkers with swivelling brass eyelets to the lower lip of each trap entry slit using $10.2 \mathrm{~cm}$ (4”) cable ties (Fig. 1A). The sinkers were evenly spaced along the entry slit, with one in the middle, and two attached $7 \mathrm{~cm}$ from the outer edge. The sinkers expanded the size of the trap entrance to approximately $2 \mathrm{~cm}$ at its widest point. For the second modification, we attached a 26 x $44 \mathrm{~cm}$ panel of black, fibreglass window screen $(1 \mathrm{x} 1 \mathrm{~mm}$ mesh size) to both the top and bottom of each trap entry tunnel (Fig. 1B). We used braided polyester string $(0.825 \mathrm{~mm}$ diameter $)$ to stitch these panels on top of the existing mesh. The panels were aligned so that a $4 \mathrm{~cm}$ wide strip of mesh extended through the trap entrance, which could be folded under the entry slit lip and stitched in place. For the third modification, we placed a thin strip of fibreglass window screen on the inside of the trap, adjacent to the entrance, which was designed to aid green crabs in pulling themselves through the restrictive opening (Fig. 1C). We cut a 4 x $54 \mathrm{~cm}$ strip of mesh and folded both ends to create a $42 \mathrm{~cm}$ long strip. The folded, reinforced ends were then attached to the inside walls of the trap using three $10.2 \mathrm{~cm}\left(4^{\prime \prime}\right)$ cable ties. Once attached, there was minimal slack left in the mesh strip, providing a flexible, yet stable surface for green crabs to grasp. The edge adjacent to the trap entrance was then loosely attached to the lower lip of the entry slit using three evenly spaced, partially-tightened cable ties. For the fourth modification, we used braided polyester string $(0.825 \mathrm{~mm}$ diameter $)$ to hold the trap entrance open (Fig. 1D). We used a $21 \mathrm{~cm}$ long piece of string to hold the upper and lower half of the entry slit open at the midpoint. The string was passed through either the top or bottom panel of the trap and tied to create a $7 \mathrm{~cm}$ loop. Once secured, the string created an oval-shaped 
102 opening, and increased the size of the trap entrance to approximately $6 \mathrm{~cm}$ at its widest point. For

103 convenience, we named these trap modifications the sinker, mesh, assist, and string

104 modifications, respectively, with an unmodified Fukui trap serving as our control.

1052.2 Fieldwork

106 We conducted our experiment in Fox Harbour, NL and North Harbour, NL during the

107 summer of 2016 (Fig. 2). We ran the experiment for 26 days in total at Fox Harbour (June 15-18,

108 June 21-25, June 28-July 5, July 12-16, August 4-12), and 9 days in total at North Harbour (July

109 18-27). We set traps in fleets of five, which consisted of the four different modified traps (i.e.,

110 sinker, mesh, assist, string) and an unmodified control trap. These fleets were deployed

111 repeatedly in fixed locations across each study site, which we referred to as 'blocks'. The order

112 of the five traps was randomized within each block. There were three blocks at Fox Harbour

113 (FoxA, FoxB, and FoxC) and three in North Harbour (NorthA, NorthB, and NorthC) (Fig. 2).

114 These blocks were spread out to provide sampling positions at multiple points within the two

115 bays in which we conducted the experiment. The specific location of each block was selected

116 based on accessibility by road and the presence of green crabs following a pilot study conducted

117 in early June 2016 (North Harbour: June 2; Fox Harbour: June 8-9).

118 We baited each trap with approximately $200 \mathrm{~g}$ of Atlantic herring (Clupea harengus) that

119 was thawed, cut into pieces, and placed in a perforated plastic bait container suspended inside the

120 centre of the trap. We chose to use herring because it is the standard bait used by Fisheries and

121 Oceans Canada (DFO) for green crab mitigation efforts (Gillespie et al., 2007; DFO, $2011 \mathrm{a}$ ).

122 Prior to each deployment, each trap was assigned a unique identification number and the order of

123 traps within each fleet was pre-determined using a random sequence generator in $\mathrm{R}$ ( $\mathrm{R}$ Core

124 Team, 2015). We deployed the traps from shore during low tide so that they remained 
125 consistently submerged for the duration of the deployment. The traps within each fleet were

126 placed approximately $10 \mathrm{~m}$ apart, matching the spacing used in other Fukui trap-based studies

127 (Gillespie et al., 2007, 2015; Behrens Yamada \& Gillespie, 2008; Curtis et al., 2015; Duncombe

$128 \&$ Therriault, 2017; Bergshoeff et al., 2018). It is possible that the distance between adjacent

129 traps could have had an influence on catch rates through bait attractant interference; therefore,

130 we were careful to maintain consistent $10 \mathrm{~m}$ spacing between traps throughout the experiment.

131 Our objective was to deploy each fleet for a 24-hour period, retrieving them at low tide the

132 following day.

133 Upon retrieval of the traps, we placed all captured green crabs in large polyethylene bags

$134(80 \mathrm{~cm} \times 36 \mathrm{~cm})$ along with a waterproof label indicating the unique identification number

135 assigned to each trap. All bycatch species were visually identified to the lowest possible

136 taxonomic level, recorded, and released as soon as possible. Once the catch was processed, the

137 traps were baited with fresh herring, and re-deployed in a new random sequence. We repeated

138 the entire process across all three blocks. All captured green crabs were euthanized by freezing,

139 and prior to disposal they were counted, sexed, and measured. We measured the carapace width

140 of each green crab using digital Vernier calipers between the fourth and fifth anterolateral

141 carapace spines (i.e., notch to notch).

142 This project was approved as a 'Category A' study by the Institutional Animal Care

143 Committee at Memorial University of Newfoundland as it involved only invertebrates (project \#

144 15-02-BF), and our field experiment was conducted under experimental license NL-3271-16

145 issued by DFO. 


\section{$146 \quad 2.3$ Statistical analysis}

\section{2.3.1 Catch vs. trap type}

148 We conducted all analyses and produced all figures using R Statistical Software (R Core

149 Team, 2015). We employed a generalized linear mixed-effects model (GLMM) to test whether

150 the number of green crabs captured per trap differed with trap type, and whether the deployment

151 location (i.e., block) had an influence on catch. GLMMs are powerful statistical models that can

152 be used to analyze non-normal data that involves random effects (Bolker et al., 2009). Our

153 deployment durations were mostly consistent from one deployment to the next (mean $=23.9 \mathrm{~h}$;

$154 \mathrm{SD}=2.4)$. Therefore, our CPUE was defined as the total number of green crabs captured per

155 each individual trap deployment. To model catch as a function of the covariates, a negative

156 binomial GLMM with a log link function was used [Eqn. (1)]. We had initially tested a Poisson

157 GLMM, but found it to be overdispersed; therefore, we switched to a negative binomial

158 distribution. The log link function ensured positive fitted values, and the negative binomial

159 distribution was appropriate for our count data. We followed the equation nomenclature and style

160 for presenting statistical models as outlined in Zuur \& Ieno, 2016.

161 The fixed covariates in our model are trap type (categorical with five levels: control,

162 sinker, mesh, assist, string), and block (categorical with six levels: FoxA, FoxB, FoxC, NorthA,

163 NorthB, NorthC). We had tested for an interaction between trap type and location (categorical

164 with two levels: Fox Harbour, North Harbour), but found it to be non-significant; therefore, we

165 removed it from our final model. In general, we found green crab distributions to be patchy, with 166 a great deal of local-scale variation within each site. Therefore, block was included as a covariate

167 to model the effect of spatial variation between the deployment locations. We deployed 15 traps

168 per day and CPUE was not uniform across days; therefore, we included study day as a random 
169 intercept. This allowed us to incorporate the dependency structure among observations within the

170 same study day, and to account for temporal variations in the environment (e.g., water

171 temperature, weather).

172 To determine our final model we conducted stepwise backward model simplification,

173 dropping non-significant terms (e.g., duration) one at a time until all terms in our model were

174 statistically significant (procedure outlined in Crawley, 2012). Our final model was specified as

175 follows:

$$
\operatorname{Catch}_{i j} \sim N B\left(\mu_{i j}, k\right)
$$

$$
\text { StudyDay }_{i} \sim N\left(0, \sigma^{2}\right)
$$

183 Core Team, 2015). We verified the model assumptions by plotting residual versus fitted values,

184 residuals versus covariates in the model, and residuals versus covariates excluded from the 185 model.

\subsubsection{Carapace width vs. trap type}

We constructed a linear mixed-effects model (LME) to test whether the mean carapace width of captured green crabs differed with trap type, and whether there was an interaction

189 between carapace width for male and female green crabs (i.e., sex), and trap type. The carapace

190 width measurements were normally distributed; therefore, we assumed a normal distribution in 191 our model with an identity link [Eqn. (2)]. 
The fixed covariates in our models were trap type (categorical with five levels: control,

193 sinker, mesh, assist, string), sex (categorical with two levels: female, male), and block

194 (categorical with six levels: FoxA, FoxB, FoxC, NorthA, NorthB, NorthC). Block was included

195 in our model to account for any spatial variability between green crab populations in Fox

196 Harbour and North Harbour. We tested for an interaction between sex and trap type. Finally, we

197 included study day as a random intercept to incorporate the dependency among observations of

198 the same study day, and to account for temporal variations. Our final model was specified as

199 follows:

200

$$
\text { CarapaceWidth }_{i j} \sim N\left(\mu_{i j}, \sigma^{2}\right)
$$

To fit models in Eqn. (2) we used the nlme package (Pinhero et al., 2017) in R (R Core

Team, 2015). We verified the model assumptions by plotting residual versus fitted values. The residuals met the assumptions for homogeneity, normality, and independence.

\section{Results}

\subsection{Trapping effort and bycatch}

We captured a total of 17,615 green crabs across 520 deployments (104 fleets) with an

212 average catch of 34 green crabs per trap $(\mathrm{SD}=25.4)$. We deployed 390 traps (78 fleets) in Fox

213 Harbour, and 130 traps (26 fleets) in North Harbour (Table 1). We lost data from a single fleet 
214 (NorthA, $n=5$ traps) in North Harbour on July 23 because the traps were washed ashore during

215 a storm event. Deployment durations ranged from $13.8-27.1 \mathrm{~h}($ mean $=23.9 \mathrm{~h}$; SD $=2.4)$. Short

216 deployment durations can be attributed to the logistical challenges of switching from trap

217 deployments during evening low tide, to morning low tide.

218 Bycatch for both the standard and modified Fukui traps was minimal (Table 2). The most

219 common occurrence of bycatch was rock crab (Cancer irroratus) in traps with the sinker and 220 assist modifications. In total, we captured 157 rock crabs (mean $=0.3$ rock crabs per trap; $\mathrm{SD}=$

$2210.7)$ across all 520 deployments.

222

223

224

225

226

227

228

229

230

231

232

233

234

236

235 The output of our model is presented in Table 4, and the parameter estimates for each

\subsection{Effect of trap type on CPUE}

The actual number of green crabs caught in each trap type during our field experiment is summarized in Table 3. Our statistical model revealed that Fukui traps equipped with the sinker $(\mathrm{GLMM}: \beta=0.461$, S.E. $=0.074, z=6.220, p<0.001), \operatorname{mesh}(\mathrm{GLMM}: \beta=0.253$, S.E. $=0.075$, $z=3.370, p=0.001)$, and assist (GLMM: $\beta=0.593$, S.E. $=0.074, z=8.030, p<0.001)$

modifications all caught significantly more green crabs than the unmodified control traps (Fig. 3). The catch rate was not significantly different between traps with the string (GLMM: $\beta=$ 0.029 , S.E. $=0.075, z=0.380, p=0.705)$ modification and the control traps. There was some variability in catch rates between the different experimental blocks, and the catch rate at FoxA was significantly higher than all other experimental blocks (Fig. S1). During the development of our model we found there was no significant interaction between trap type and location; therefore, despite spatial variations in catch between blocks, the CPUE of the modified traps was not influenced by the location. modified trap can be explained as follows: First, the mesh trap caught 1.29 (95\% CI [1.11, 1.49]) 
237 times as many green crabs as the control trap which translates to a $29 \%$ increase in catch relative

238 to the standard Fukui trap. Second, the sinker trap caught 1.59 (95\% CI $[1.37,1.83)$ times as

239 many green crabs as the control trap which translates to a 59\% increase in catch relative to the

240 standard Fukui trap. Third, the assist trap caught 1.81 (95\% CI [1.57, 2.09]) times as many green

241 crabs as the control trap which translates to an $81 \%$ increase in catch relative to the standard

242 Fukui trap. Finally, the string trap did not show any statistically significant improvement over

243 the control trap, catching 1.03 (95\% CI $[0.89,1.19])$ times as many green crabs. This translates

244 to a $3 \%$ increase in CPUE relative to the standard Fukui trap.

\subsection{Effect of trap type of crab size}

We measured 17,598 green crabs in total (Fig. 4A). Across all trap types, carapace width for male green crabs ranged from $21.1-77.0 \mathrm{~mm}($ mean $=52.4 \mathrm{~mm}$; $\mathrm{SD}=7.7)$. For female green crabs, carapace width ranged from $25.4-60.8 \mathrm{~mm}($ mean $=41.8 \mathrm{~mm}$; SD $=4.8)$. Male green crabs averaged significantly larger than female green crabs by $9.8 \mathrm{~mm}$ (LME: $\beta=9.823$, S.E. $=0.369, t=26.636, p<0.001)$. For female green crabs, there was no significant difference in average carapace width between the modified traps and the unmodified control (Table 5). There was a significant interaction between sex and trap type. Both the sinker (LME: $\beta=1.213$, S.E. $=0.486, t=2.494, p=0.013)$ and string $(\mathrm{LME}: \beta=1.914$, S.E. $=0.531, t=3.602, p<$ 0.001) modifications caught male green crabs that were larger than the male crabs caught in the control traps. All parameter estimates, and the specific results of block can be found in Table 5 . In general, green crabs caught in North Harbour were larger than green crabs caught in Fox Harbour, demonstrating the variability in green crab populations from one location to the next. 


\section{Discussion}

259

260

261

262

263

264

265

266

267

268

269

270

271

272

273

274

275

276

277

278

279

280

\subsection{Modified trap performance}

Modifications made to fishing gear designs can have a considerable impact on catch rates and catch composition. Modifications can be used to promote the switch to more sustainable fishing gears (Ljungberg et al., 2016; Meintzer, Walsh \& Favaro, 2018), reduce the bycatch of non-target species (Broadhurst, 2000; Furevik et al., 2008; Favaro, Duff \& Côté, 2013; Serena, Grant \& Williams, 2016), improve selectivity for a target species (Moran \& Jenke, 1990;

Boutson et al., 2009; Ovegård et al., 2011; Winger \& Walsh, 2011), and increase the overall catch rate of a fishing gear (Sheaves, 1995; Nguyen et al., 2017; Meintzer, Walsh \& Favaro, 2018). In this study, we tested four different modifications designed to improve the efficiency of the Fukui trap as a tool for removing green crabs from invaded ecosystems. These modifications were specifically developed to address the most common inefficiencies in the design of the Fukui trap identified in Bergshoeff et al., 2018 - primarily the entanglement of green crabs in the trap mesh, and the restrictive trap opening that inhibits the successful entry of green crabs into the trap.

Our least effective design was the string modification, which did not show any significant improvement in green crab CPUE when compared to the control. We suspect this low CPUE can be attributed to a high frequency of escape events. The string modification was designed to expand the trap entrance to approximately $6 \mathrm{~cm}$ at its widest point. By contrast, the control trap's entrance remains tightly closed in its default position. This restrictive entrance does not allow green crabs to escape once captured; however; it also makes it harder for crabs to enter the traps (Bergshoeff et al., 2018). A large trap entrance facilitates entry, but can also increase the frequency of escapes, thereby reducing capture efficiency (Archdale et al., 2007). In our design, 
281 the strings caused both the upper and lower panels of the entry slit to curve outwards (Fig. 1D).

282 We suspect this made it relatively easy for captured green crabs to climb out and escape,

283 nullifying the benefits of a larger trap entrance. To mitigate this issue, our design could likely be

284 improved by adjusting the length of the strings to create a smaller opening. However, despite the

285 string modification being quick and easy to install, we found the overall design impractical, as

286 the positioning of the strings made it difficult to clear captured green crabs from the trap once it

287 was retrieved.

288 We designed the mesh modification to facilitate the entry of green crabs into the Fukui

289 trap by preventing their pereopods and anterolateral carapace spines from becoming entangled in

290 the trap mesh during entry attempts (Bergshoeff et al., 2018). We found the mesh modification

291 was effective, capturing 29\% more green crabs than the standard Fukui trap; however, we

292 suspect that green crabs still encountered difficultly entering the trap. Although the mesh

293 modification likely minimized entanglement, the fibreglass window screen panels overlaid on the

294 existing trap mesh appeared to increase the tension of the entry slit. This likely made it more

295 difficult for larger crabs to enter the trap (Fig. 4A). Furthermore, the slippery texture of the

296 window screen may have made it difficult for crabs to gain enough traction to force themselves

297 through the trap entrance. Our modification could likely be improved by replacing the window

298 screen with a proprietary netting material designed for fishing gear. However, we found the

299 process of stitching the mesh panels to the Fukui trap by hand was time-consuming, which could

300 make adopting this modification impractical for large-scale green crab removal programs.

301 We designed the sinker modification to minimize the difficulty that green crabs

302 experience when attempting to pass through the Fukui trap entrance (Bergshoeff et al., 2018).

303 We found this modification to be simple and effective, producing catch rates that were $59 \%$ 
304 greater than the control. Unlike the string modification, which was also designed to increase the

305 size of the trap opening, the sinker modification did not appear to facilitate frequent escape

306 events. We suspect that the three $28.3 \mathrm{~g}$ (1-oz) sinkers expanded the lower half of the entry slit

307 enough for green crabs to navigate through without much difficulty, but not enough that they

308 were able to easily escape once captured, as inferred with the string modification. If we had

309 chosen to use more weight, the trap entrances may have become too large, facilitating the escape

310 of captured crabs. Although it is likely that some green crabs were able to successfully exit the

311 trap, we suspect that most green crabs lacked the maneuverability to make their way back

312 through once inside the trap. In the field, we found the sinker modification to be durable,

313 withstanding repeated deployments for a cumulative total of $2,482.3 \mathrm{~h}$ without requiring any

314 maintenance. Furthermore, unlike the string modification, traps equipped with the sinker

315 modification were easily emptied upon retrieval. Finally, installing this modification took the

316 least amount of time and effort, and could be used to quickly modify a large fleet of standard

317 Fukui traps. These factors make the sinker modification a practical tool for capturing green crabs

318 on a large-scale.

319 The assist modification was designed to aid green crabs in entering the Fukui trap,

320 without increasing the size of the trap entrance. Our previous study revealed that even if a green

321 crab was able to avoid entanglement and reach one of its pereopods or chelipeds through the

322 entrance of a standard Fukui trap, there was nothing for it to grab hold of to pull itself through

323 the opening. This lack of assistance would often result in green crabs failing to successfully enter

324 the trap (Bergshoeff et al., 2018). Through the addition of the assist modification, we observed a

325 dramatic $81 \%$ increase in the CPUE of the Fukui trap. However, despite the success of this

326 modification in increasing CPUE, our current design would need improvements to make it 
327 practical for large-scale green crab removal efforts. Installation of the assist modification was

328 tedious and time-consuming, and our prototype version lacked the durability required for

329 repetitive usage and often had to be repaired over the course of our experiment. Like the mesh

330 modification, the durability of the assist modification could likely be improved by replacing the

331 window screen with a proprietary netting material designed for fishing gear. Alternatively, it is

332 possible that some form of rigid plate could provide similar gains in CPUE. However, materials

333 with a smooth surface should likely be avoided (e.g., a plastic plate), as these can be difficult for

334 crustaceans to crawl over (Miller, 1979; Favaro, Duff \& Côté, 2013). If the durability of the

335 assist modification can be improved this design has the potential to greatly increase the

336 efficiency of green crab removal efforts.

For female green crabs, there was no significant difference in carapace width between our modified traps and the standard Fukui trap. For male green crabs, traps equipped with the sinker and string modifications caught males that were larger than the unmodified control. These two modifications were the only designs where the size of the trap entrance was increased, which would explain their ability to capture larger green crabs. In general, female green crabs are

342 smaller than male green crabs (Best, McKenzie \& Couturier, 2017). Therefore, the benefits of a

343 larger entrance in both the sinker trap and the string trap are only realized by larger male green

344 crabs, which likely experienced greater difficulty entering the mesh, assist, and control traps due 345 to the restrictive trap entrance.

Removing large male green crabs from invaded ecosystems will likely have ecological

347 benefits because reproductive success in males is directly related to size. During the mating

348 season, male green crabs compete aggressively for access to receptive females for mating

349 (Berrill, 1982). The most important factor that determines their success in these conflicts is their 
350 size (Reid \& Naylor, 1994). These larger males have the reproductive advantage of bigger

351 gonads and more spermatophores, which ultimately enables them to fertilize more eggs, or mate

352 with a larger number of female green crabs (Styrishave, Rewitz \& Andersen, 2004).

353 Additionally, large crabs can forage to deeper depths in the sediment in search of food and can

354 take larger prey (Jensen \& Jensen, 1985; Smith, 2004). In general, these larger green crabs will

355 have an advantage over native species when it comes to competition for food (Cohen, Carlton \& 356 Fountain, 1995). Therefore, there may be ecological benefits to removing the largest crabs from

357 invaded areas, which is encouraged by our sinker and string modifications.

358 Furthermore, if future modifications can be refined to also increase the size of female 359 crabs being caught this will have further ecological benefits, as larger females are capable of

360 producing larger egg clutches and have higher reproductive success (Audet et al., 2008; Best,

361 McKenzie \& Couturier, 2017). Under favourable conditions, a single adult female green crab can

362 spawn up to 185,000 eggs per year (Broekhuysen, 1936; Cohen, Carlton \& Fountain, 1995;

363 Grosholz, E., Ruiz, 2002). Therefore, removing as many female green crabs as possible would

364 have the largest per capita impact on population growth. In our experiment, the total catch

365 composition for each trap type was mostly male, ranging from $80.2-85.4 \%$ (mean: $83.5 \%$; SD

$366=1.94)$. We did not observe any meaningful variation in the total proportion of male and female

367 green crabs caught in each trap type (Fig. 4B). The mesh modification caught a slightly greater

368 proportion of female crabs compared with the other trap types; however, these minor selectivity

369 gains are not enough to justify a shift in fishing strategy (e.g., using the mesh modification

370 instead of the sinker or assist modification). Overall, we are trying to maximize the number of

371 green crabs removed from invaded ecosystems. To accomplish this, we recommend using the 
372 sinker or assist modifications, which achieved the highest CPUE during our experiment and will

373 likely have the greatest impact on the reproductive potential of invasive green crab populations.

3744.2 Bycatch

375 When compared with fishing gears such as bottom trawls and long lines, traps and pots

376 are advantageous as they are often more selective for species and size, and they promote the live

377 release of bycatch after the gear has been retrieved (Suuronen et al., 2012; Poirier et al., 2018).

378 Our previous study in Newfoundland revealed that bycatch in the Fukui trap is minimal, and that

379 most non-target species can be released unharmed upon retrieval of the trap (Bergshoeff et al.,

380 2018). When targeting green crabs using the Fukui trap, native crustacean species are usually the

381 most common form of bycatch (Gillespie et al., 2007; Bergshoeff et al., 2018). Modifications are

382 often made to traps with the goal of reducing the bycatch of non-target species, while

383 maintaining the effectiveness of the gear at capturing target species (Zhou \& Shirley, 1997;

384 Favaro, Duff \& Côté, 2013; Serena, Grant \& Williams, 2016; Poirier et al., 2018).

385 The goal of our design modifications were to increase the overall capture efficiency of

386 the Fukui trap; therefore, there was a risk that the modified traps would also increase the bycatch

387 of non-target species. Fortunately, bycatch was minimal for all trap types, and mostly limited to

388 native rock crabs (Table 2). Rock crabs were most commonly captured in traps equipped with the

389 sinker and assist modifications. This is not surprising, as these traps were also the most effective

390 at capturing green crabs. Our modifications were designed to facilitate the entry of green crabs

391 into the Fukui trap; therefore, it makes sense that these modifications would also facilitate the

392 entry of other crab species (i.e., rock crab). In both this study and our previous study, we did not

393 observe any predation or mortality of rock crab bycatch (Bergshoeff et al., 2018). Overall,

394 bycatch when using our modified Fukui traps in the coastal waters of Newfoundland appears to 
395 be of minimal concern. That said, the green crab is a worldwide invader. Therefore, prior to

396 adopting these modifications in areas with a greater density of catchable bycatch species (e.g.,

397 along the west coast of Canada), they should initially be used with caution until the impact on

398 native species is known.

399

400

401

402

403

404

405

406

407

408

409

410

411

412

413

414

415

416

417

\subsection{Practical application}

We designed our trap modifications to be simple and practical, so that they could be applied to Fukui traps with minimal effort. Overall, based on durability and performance, we conclude that the sinker modification is an excellent option for improving the efficiency of the Fukui trap as a selective green crab capture tool. The assist modification demonstrated impressive performance; however, durability was an issue which currently limits its practicality for large-scale use. If these durability challenges are addressed, then this modification would be the most effective way to increase green crab CPUE within removal programs. However, the sinker modification has the added advantage of catching larger male green crabs. For both male and female green crabs, larger body size is associated with greater reproductive success and fecundity (Kelley et al., 2015). It has been shown that continuous trapping and the removal of larger crabs from an invaded area can cause a demographic shift towards a younger population, with reduced body mass and reproductive potential (Duncombe \& Therriault, 2017).

Furthermore, a reduction in the average carapace width of green crabs can cause a shift in their ecological role, from primary predators to potential prey for native crustaceans and shorebirds (DFO, 2011b). Therefore, even though the increase in average carapace width for the sinker modification is small, it could provide an advantage to green crab removal programs over time. In this study, we chose to individually address the common inefficiencies of the Fukui trap; however, to further improve the trap's efficiency it may be possible to combine multiple 
418 design modifications into a single modified trap. For example, a Fukui trap equipped with the

419 sinker and mesh modification would address both the restrictive trap entrance, and the issue of

420 entanglement in the mesh. In addition to trap design modifications, future studies could

421 investigate improved techniques for attracting green crabs to the trap itself. The use of white and

422 purple LED lights has been shown to significantly improve the catchability of snow crab

423 (Chionoecetes opilio) traps (Nguyen et al., 2017). Similarly, it may be possible to increase the

424 CPUE of Fukui traps using artificial lighting to attract green crabs. Furthermore, the type of bait

used to attract a target species can also have an impact on CPUE (Miller, 1990; Woll et al., 2001;

426 Beecher \& Romaire, 2010; Vazquez Archdale \& Kawamura, 2011). For green crab, it has been

427 shown that Atlantic cod (Gadus morhua) and short-fin squid (Illex illecebrosus) can produce

428 green crab catch rates that are statistically greater than Atlantic herring (Butt, 2017). When

429 combined, these techniques could further increase the efficiency of the Fukui trap as a green crab 430 capture tool.

431 Moving forward, it is essential that ongoing green crab removal programs continue to

432 embed gear design studies within them. It would be a missed opportunity to incorporate the top

433 performing modifications that we tested in this study into green crab removal efforts without

434 further replicating the results against additional control traps. By replicating the results, it would

435 be possible to quantify the benefits of making a switch to modified traps. When testing new

436 modified Fukui traps, a portion of the traps that are being fished should always be devoted to

437 controlled experiments to refine these modifications, until incremental innovation is no longer

438 yielding benefits. For example, our sinker modification demonstrated a 59\% increase in green

439 crab CPUE; however, incremental innovations to this design (e.g., using both lighter and heavier

440 sinkers) could pinpoint the optimal design that maximizes CPUE and green crab capture 
441 efficiency. Furthermore, by incorporating small-scale gear design studies within green crab

442 management programs we can begin to build a culture around making invasive species fishing 443 gear as efficient and effective as possible.

\section{5. Conclusion}

445 In summary, this study demonstrates that dramatic improvements in the performance of 446 the Fukui trap can be achieved through simple design modifications. Due to the widespread use 447 and versatility of the Fukui trap as a green crab removal tool, it was important that these 448 modifications were simple, durable, and effective. We conclude that the sinker modification 449 meets all these requirements, and that existing Fukui traps can be easily retrofitted with this 450 design for use on a large-scale. The assist modification is also an excellent choice for improving 451 green crab CPUE; however, this design needs durability improvements before it is suitable for 452 use in large-scale green crab removal programs. This emphasises the importance of embedding 453 gear design experiments into ongoing green crab removal efforts. In doing so, incremental 454 improvements can be made to determine the optimal gear design for improving green crab CPUE 455 with Fukui traps. Intensive trapping using the standard Fukui trap has already proven to be an 456 effective technique for reducing green crab populations (Gillespie et al., 2007; DFO, 2011b,a). 457 Therefore, we hope that our recommended design modifications will be adopted and refined by 458 green crab removal programs as an efficient and selective tool to further reduce green crab 459 populations in invaded ecosystems. 


\section{6. Acknowledgements}

461 We would like to thank all individuals who contributed to this project and are especially

462 grateful to Mary Alliston Butt for her assistance with fieldwork. We also thank Maggie Folkins

463 for her assistance in the field. We thank DFO for providing the Fukui traps that were used in this

464 study. We thank Fox Harbour residents, Bob Buckmaster and Gerard O'Leary for access to

465 private property and for their genuine interest in this research. Finally, we would like to

466 respectfully acknowledge that we conducted this research on the unceded, unsurrendered

467 ancestral lands of the Mi'kmaq and Beothuk, and the island of Newfoundland as the ancestral

468 homelands of the Mi'kmaq and Beothuk. 


\section{References}

470 Archdale MV., Añasco CP., Kawamura Y., Tomiki S. 2007. Effect of two collapsible pot designs

471 on escape rate and behavior of the invasive swimming crabs Charybdis japonica and

472 Portunus pelagicus. Fisheries Research 85:202-209. DOI: 10.1016/j.fishres.2007.02.008.

473 Audet D., Miron G., Moriyasu M., Audet Dominique; Miron GMM. 2008. Biological

474 characteristics of a newly established green crab (Carcinus maenas) population in the

475 southern Gulf of St. Lawrence, Canada. Journal of Shellfish Research 27:427-441. DOI:

$476 \quad 10.2983 / 0730-8000(2008) 27[427:$ bcoane $] 2.0 . c o ; 2$.

477 Bates D., Mächler M., Bolker B., Walker S., Christensen RHB., Singmann H., Dai B.,

478 Grothendieck G., Green P. 2017. Package “Ime4”. R package version 1.1-13,

479 https://github.com/lme4/lme4/.

480 Bax NJ., Hayes K., Marshall A., Parry D., Thresher R. 2002. Man-made marinas as sheltered

481 islands for alien marine organisms: Establishment and eradication of an alien invasive

482 marine species. In: Veitch CR, Clout NM eds. Turning the tide: the eradication of invasive

483 species. Gland, Switzerland: IUCN SSC Invasive Species Specialist Group, 26-39. DOI:

$484 \quad 10.1366 / 0003702991946064$.

485 Bax N., Williamson A., Aguero M., Gonzalez E., Geeves W. 2003. Marine invasive alien

486 species: a threat to global biodiversity. Marine Policy 27:313-323. DOI: 10.1016/S0308-

$487 \quad 597 X(03) 00041-1$.

488 Beecher LE., Romaire RP. 2010. Evaluation of baits for harvesting Procambarid crawfishes with

489 emphasis on bait type and bait quantity. Journal of Shellfish Research 29:13-18. DOI:

$490 \quad 10.2983 / 035.029 .0106$. 
491 Behrens Yamada S. 2001. Global Invader: The European Green Crab. Corvallis, Oregon:

$492 \quad$ Oregon Sea Grant.

493 Behrens Yamada S., Gillespie GE. 2008. Will the European green crab (Carcinus maenas)

494 persist in the Pacific Northwest? ICES Journal of Marine Science 65:725-729. DOI:

$495 \quad$ 10.1093/icesjms/fsm191.

496 Bergshoeff JA., McKenzie CH., Best K., Zargarpour N., Favaro B. 2018. Using underwater

497 video to evaluate the performance of the Fukui trap as a mitigation tool for the invasive

498 European green crab (Carcinus maenas) in Newfoundland, Canada. PeerJ 6:e4223. DOI:

$499 \quad 10.7717 /$ peerj.4223.

500 Bergshoeff JA., Zargarpour N., Legge G., Favaro B. 2017. How to build a low-cost underwater

501 camera housing for aquatic research. FACETS 2:150-159. DOI: 10.1139/facets-2016-0048.

502 Berrill M. 1982. The life cycle of the green crab Carcinus maenas at the northern end of its

503 range. Journal of Crustacean Biology 2:31-39.

504 Best K., McKenzie CH., Couturier C. 2017. Reproductive biology of an invasive population of

505 European green crab, Carcinus maenas, in Placentia Bay, Newfoundland. Management of

$506 \quad$ Biological Invasions 8:247-255.

507 Bolker BM., Brooks ME., Clark CJ., Geange SW., Poulsen JR., Stevens MHH., White JSS.

508 2009. Generalized linear mixed models: a practical guide for ecology and evolution. Trends

$509 \quad$ in Ecology and Evolution 24:127-135. DOI: 10.1016/j.tree.2008.10.008.

510 Boutson A., Mahasawasde C., Mahasawasde S., Tunkijjanukij S., Arimoto T. 2009. Use of

511 escape vents to improve size and species selectivity of collapsible pot for blue swimming 

008-0010-z.

514 Broadhurst MK. 2000. Modifications to reduce bycatch in prawn trawls: A review and 515 framework for development. Reviews in Fish Biology and Fisheries 10:27-60. DOI: $516 \quad 10.1023 / \mathrm{A}: 1008936820089$.

517 Broekhuysen GJ. 1936. On development, growth and distribution of Carcinides maenas (L.). $518 \quad$ Archives Néerlandaises de Zoologie 2:257-400.

519 Butt MA. 2017. Bait selection study of the invasive European green crab (Carcinus maenas) in 520 Newfoundland, Canada. University Centre of the Westfjords Master.

521 Cohen AN., Carlton JT., Fountain MC. 1995. Introduction, dispersal and potential impacts of the 522 green crab Carcinus maenas in San Francisco Bay, California. Marine Biology 122:225523237.

524 Crawley MJ. 2012. The R book. Chichester, UK: John Wiley \& Sons Ltd.

525 Culver CS., M. Kuris A. 2000. The apparent eradication of a locally established introduced 526 marine pest. Biological Invasions 2:245-253. DOI: 10.1023/A:1010082407254.

527 Curtis LJF., Curtis DL., Matkin H., Thompson M., Choi F., Callow P., Gillespie GE., Terriault 528 TW., Pearce CM. 2015. Evaluating transfers of harvested shellfish products, from the west 529 to the east coast of Vancouver Island, as a potential vector for European green crab 530 (Carcinus Maenus) and other non-indigenous invertebrate species. DFO Can. Sci. Advis. $531 \quad$ Sec. Res. Doc. 2015/014:vi + 74 p.

532 Darling JA., Bagley MJ., Roman J., Tepolt CK., Geller JB. 2008. Genetic patterns across 
multiple introductions of the globally invasive crab genus Carcinus. Molecular Ecology

DFO. 2011a. Proceedings of the Regional Advisory Process on green crab, Carcinus maenas, populations and mitigations in the Newfoundland and Labrador region. DFO Can. Sci. Advis. Sec. Proceed. Ser. 2011/020.

DFO. 2011b. Ecological assessment of the invasive European green crab (Carcinus maenas) in Newfoundland 2007-2009. DFO Can. Sci. Advis. Sec. Sci. Advis. Rep.:2011/033.

Duncombe LG., Therriault TW. 2017. Evaluating trapping as a method to control the European green crab, Carcinus maenas, population at Pipestem Inlet, British Columbia. Management of Biological Invasions 8:235-246.

Favaro B., Duff SD., Côté IM. 2013. A trap with a twist: evaluating a bycatch reduction device to prevent rockfish capture in crustacean traps. ICES Journal of Marine Science 70:114-

Furevik DM., Humborstad OB., Jørgensen T., Løkkeborg S. 2008. Floated fish pot eliminates 122. bycatch of red king crab and maintains target catch of cod. Fisheries Research 92:23-27.

549 Garbary DJ., Miller AG., Williams J., Seymour NR. 2014. Drastic decline of an extensive 550 eelgrass bed in Nova Scotia due to the activity of the invasive green crab (Carcinus maenas). Marine Biology 161:3-15. DOI: 10.1007/s00227-013-2323-4.

552 Gillespie GE., Norgard TC., Anderson ED., Haggarty DR., Phillips AC. 2015. Distribution and 553 biological characteristics of European green crab, Carcinus maenas, in British Columbia, 
555 Gillespie GE., Phillips AC., Paltzat DL., Therriault TW. 2007. Status of the European green

556 crab, Carcinus maenas, in British Columbia - 2006. Canadian Technical Report of

$557 \quad$ Fisheries and Aquatic Sciences 2700:39 p.

558 Grosholz, E., Ruiz G. 2002. Management plan for the European green crab Submitted to the 559 Aquatic Nuisance Species Task Force Green Crab Control Committee Frederick Kern , $560 \quad$ Chair Edited by Edwin Grosholz and Gregory Ruiz. :55.

561 Jensen KT., Jensen JN. 1985. The importance of some epibenthic predators on the density of

562 juvenile benthic macrofauna in the Danish Wadden Sea. Journal of Experimental Marine Biology and Ecology 89:157-174. DOI: 10.1016/0022-0981(85)90124-8.

Kahle D., Wickham H. 2013. ggmap: Spatial Visualization with ggplot2. The R Journal 5:144161.

Kelley AL., de Rivera CE., Grosholz ED., Ruiz GM., Yamada SB., Gillespie G. 2015.

567 Thermogeographic variation in body size of Carcinus maenas, the European green crab.

568 Marine Biology 162:1625-1635. DOI: 10.1007/s00227-015-2698-5.

Ljungberg P., Lunneryd SG., Lövgren J., Königson S. 2016. Including cod (Gadus morhua) behavioural analysis to evaluate entrance type dependent pot catch in the Baltic sea. Journal of Ocean Technology 11:48-63. 
DOI: $10.1890 / 04-0922$.

576 Malyshev A., Quijón PA. 2011. Disruption of essential habitat by a coastal invader: New

577 evidence of the effects of green crabs on eelgrass beds. ICES Journal of Marine Science

$578 \quad 68: 1852-1856$. DOI: 10.1093/icesjms/fsr126.

579 Matheson K., Gagnon P. 2012. Temperature mediates non-competitive foraging in indigenous

$580 \quad$ rock (Cancer irroratus Say) and recently introduced green (Carcinus maenas L.) crabs from

$581 \quad$ Newfoundland and Labrador. Journal of Experimental Marine Biology and Ecology 414-

582 415:6-18. DOI: 10.1016/j.jembe.2012.01.006.

583 Matheson K., McKenzie CH. 2014. Predation of sea scallops and other indigenous bivalves by 584 invasive green crab, Carcinus maenas, from Newfoundland, Canada. Journal of Shellfish

$585 \quad$ Research 33:495-501. DOI: 10.2983/035.033.0218.

586 Matheson K., McKenzie CH., Gregory RS., Robichaud DA., Bradbury IR., Snelgrove PVR.,

587 Rose GA. 2016. Linking eelgrass decline and impacts on associated fish communities to 588 European green crab Carcinus maenas invasion. Marine Ecology Progress Series 548:31-

589 45. DOI: $10.3354 / \operatorname{meps} 11674$.

590 Meintzer P., Walsh P., Favaro B. 2018. Comparing catch efficiency of five models of pot for use

591 in a Newfoundland and Labrador cod fishery. PLOS ONE 13:1-18. DOI:

$592 \quad$ 10.1371/journal.pone.0199702.

593 Miller RJ. 1979. Saturation of crab traps: Reduced entry and escapement. ICES Journal of

594 Marine Science 38:338-345. DOI: 10.1093/icesjms/38.3.338.

595 Miller RJ. 1990. Effectiveness of crab and lobster traps. Canadian Journal of Fisheries and 


$$
\text { Aquatic Sciences 47:1228-1251. DOI: 10.1139/f90-143. }
$$

597 Moran M., Jenke J. 1990. Effects of fish trap mesh size on species and size selectivity in the $598 \quad$ Australian North West Shelf trap fishery. Fishbyte 8:8-13.

599 Nguyen KQ., Winger PD., Morris C., Grant SM. 2017. Artificial lights improve the catchability 600 of snow crab (Chionoecetes opilio) traps. Aquaculture and Fisheries 2:124-133. DOI: $601 \quad$ 10.1016/j.aaf.2017.05.001.

602 Ovegård M., Königson S., Persson A., Lunneryd SG. 2011. Size selective capture of Atlantic cod 603 (Gadus morhua) in floating pots. Fisheries Research 107:239-244. DOI:

$604 \quad$ 10.1016/j.fishres.2010.10.023.

605 Pickering TR., Poirier LA., Barrett TJ., McKenna S., Davidson J., Quijón PA. 2017. Non606 indigenous predators threaten ecosystem engineers: Interactive effects of green crab and 607 oyster size on American oyster mortality. Marine Environmental Research 127:24-31. DOI: $608 \quad$ 10.1016/j.marenvres.2017.03.002.

609 Pinhero J., Bates D., Debroy S., Sarkar D., R Core Team. 2017. nlme: linear and nonlinear mixed 610 effects models. R package version 3.1-131, https://cran.r-project.org/package=nlme.

611 Poirier LA., Symington LA., Davidson J., St-Hilaire S., Quijón PA. 2017. Exploring the decline 612 of oyster beds in Atlantic Canada shorelines: potential effects of crab predation on 613 American oysters (Crassostrea virginica). Helgoland Marine Research 71:13. DOI: $614 \quad$ 10.1186/s10152-017-0493-z.

615 Poirier LA., Tang S., Mohan J., O’Connor E., Dennis E., Abdullah M., Zhou D., Stryhn H., St616 Hilaire S., Quijón PA. 2018. A novel bycatch reduction device (BRD) and its use in a 
617 directed fishery for non-indigenous green crabs (C. maenas) in Atlantic Canada. Fisheries

$618 \quad$ Research 204:165-171. DOI: 10.1016/j.fishres.2018.02.018.

619 R Core Team. 2015. R: A language and environment for statistical computing. R Foundation for 620 Statistical Computing, Vienna, Austria. URL http://www.R-project.org/.

621 Reid DG., Naylor E. 1994. Size-related mating success in the shore crab Carcinus maenas 622 (Crustacea: Brachyura). Jouranl of Zoology, London 232:397-407.

623 Roman J. 2006. Diluting the founder effect: cryptic invasions expand a marine invader's range.

624 Proceedings of the Royal Society B: Biological Sciences 273:2453-2459. DOI:

$625 \quad 10.1098 / \mathrm{rspb} .2006 .3597$.

626 Ropes JW. 1968. The feeding habits of the green crab, Carcinus maenas (L.). Fishery Bulletin $627 \quad 67: 183-203$.

628 Rossong MA., Quijón PA., Snelgrove PVR., Barrett TJ., McKenzie CH., Locke A. 2012.

629 Regional differences in foraging behaviour of invasive green crab (Carcinus maenas) 630 populations in Atlantic Canada. Biological Invasions 14:659-669. DOI: 10.1007/s10530$631 \quad 011-0107-7$.

632 Rossong MA., Williams PJ., Comeau M., Mitchell SC., Apaloo J. 2006. Agonistic interactions 633 between the invasive green crab, Carcinus maenas (Linnaeus) and juvenile American 634 lobster, Homarus americanus (Milne Edwards). Journal of Experimental Marine Biology 635 and Ecology 329:281-288. DOI: 10.1016/j.jembe.2005.09.007.

636 Serena M., Grant TR., Williams GA. 2016. Reducing bycatch mortality in crustacean traps:

637 Effect of trap design on platypus and yabby retention rates. Fisheries Research 175:43-50. 
DOI: $10.1016 /$ j.fishres.2015.11.010.

639

640

641

642

643

644

645

646

647

648

649

650

651

652

653

654

655

656

657

658

Sheaves MJ. 1995. Effects of design modifications and soak time varations on Antillean-z fish trap perfomance in a tropical estuary. Bulletin of Marine Scince 56:475-489.

Simberloff D. 2001. Eradication of island invasives: practical actions and results achieved. Trends in Ecology and Evolution 16:273-274. DOI: 10.1016/S0169-5347(01)02154-1.

Smith LD. 2004. Biogeographic differences in claw size and performance in an introduced crab predator Carcinus maenas. Marine Ecology Progress Series 276:209-222. DOI: $10.3354 /$ meps 276209 .

Styrishave B., Rewitz K., Andersen O. 2004. Frequency of moulting by shore crabs Carcinus maenas (L.) changes their colour and their success in mating and physiological performance. Journal of Experimental Marine Biology and Ecology 313:317-336. DOI: 10.1016/j.jembe.2004.08.013.

Suuronen P., Chopin F., Glass C., Løkkeborg S., Matsushita Y., Queirolo D., Rihan D. 2012. Low impact and fuel efficient fishing-Looking beyond the horizon. Fisheries Research 119-120:135-146. DOI: 10.1016/j.fishres.2011.12.009.

Vazquez Archdale M., Kawamura G. 2011. Evaluation of artificial and natural baits for the pot fishery of the sand crab Ovalipes punctatus (De Haan, 1833). Fisheries Research 111:159163. DOI: 10.1016/j.fishres.2011.07.006.

Winger PD., Walsh PJ. 2011. Selectivity, efficiency, and underwater observations of modified trap designs for the snow crab (Chionoecetes opilio) fishery in Newfoundland and Labrador. Fisheries Research 109:107-113. DOI: 10.1016/j.fishres.2011.01.025. 
659 Woll AK., Boje J., Holst R., Gundersen AC. 2001. Catch rates and hook and bait selectivity in 660 longline fishery for Greenland halibut (Reinhardtius hippoglossoides, Walbaum) at East 661 Greenland. Fisheries Research 51:237-246. DOI: 10.1016/S0165-7836(01)00249-1.

662 Zhou S., Shirley TC. 1997. Performance of two red king crab pot designs. Canadian Journal of 663 Fisheries and Aquatic Sciences 54:1858-1864. DOI: 10.1139/cjfas-54-8-1858.

664 Zuur AF., Ieno EN. 2016. A protocol for conducting and presenting results of regression-type 665 analyses. Methods in Ecology and Evolution 7:636-645. DOI: 10.1111/2041-210X.12577. 


\section{Figure 1}

The four different trap modifications: sinker (A), mesh (B), assist (C), string (D).

The red coloured objects in each Fukui trap schematic indicate the modification features. 


\section{A) Sinker}

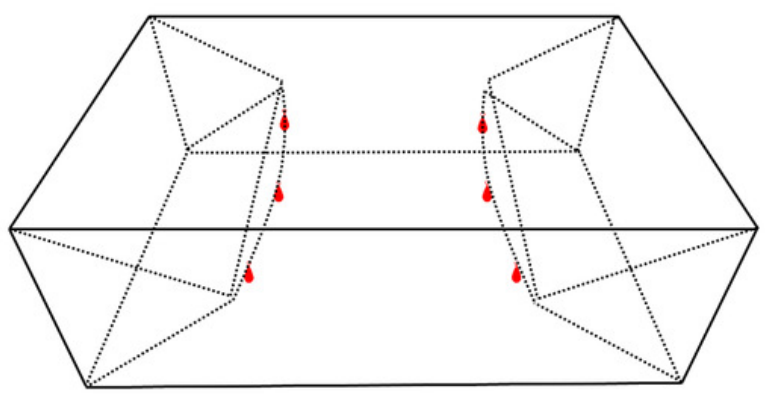

B) Mesh

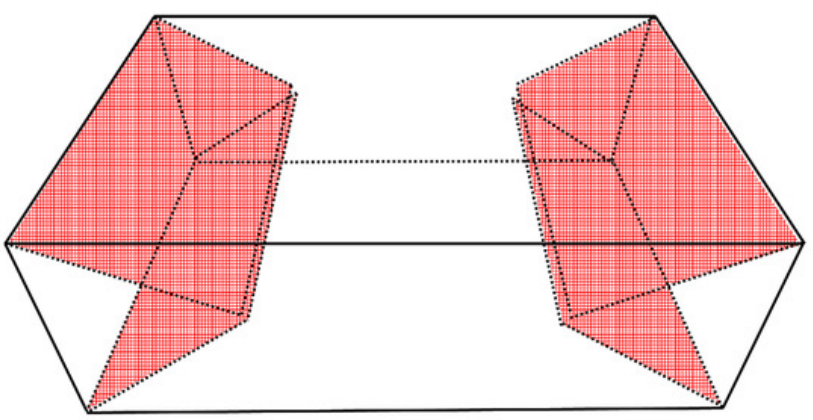

\section{C) Assist}

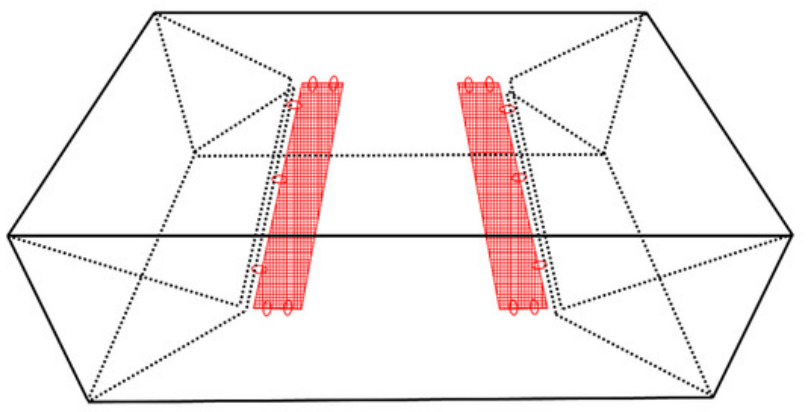

\section{D) String}

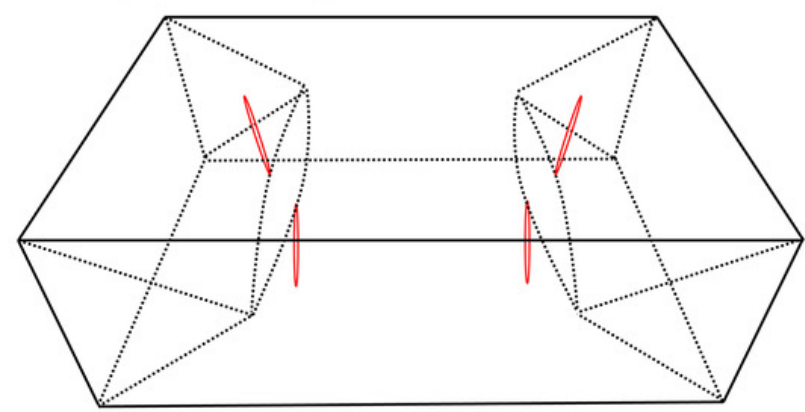

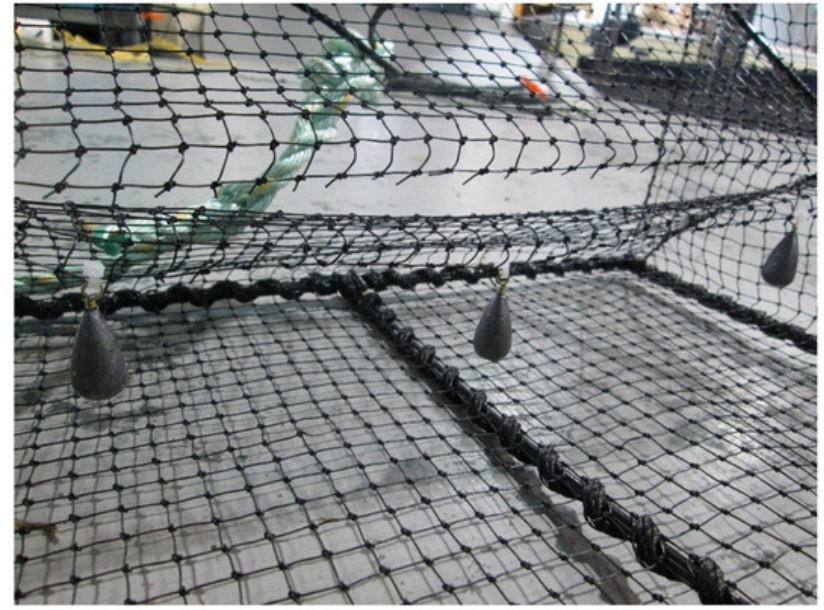
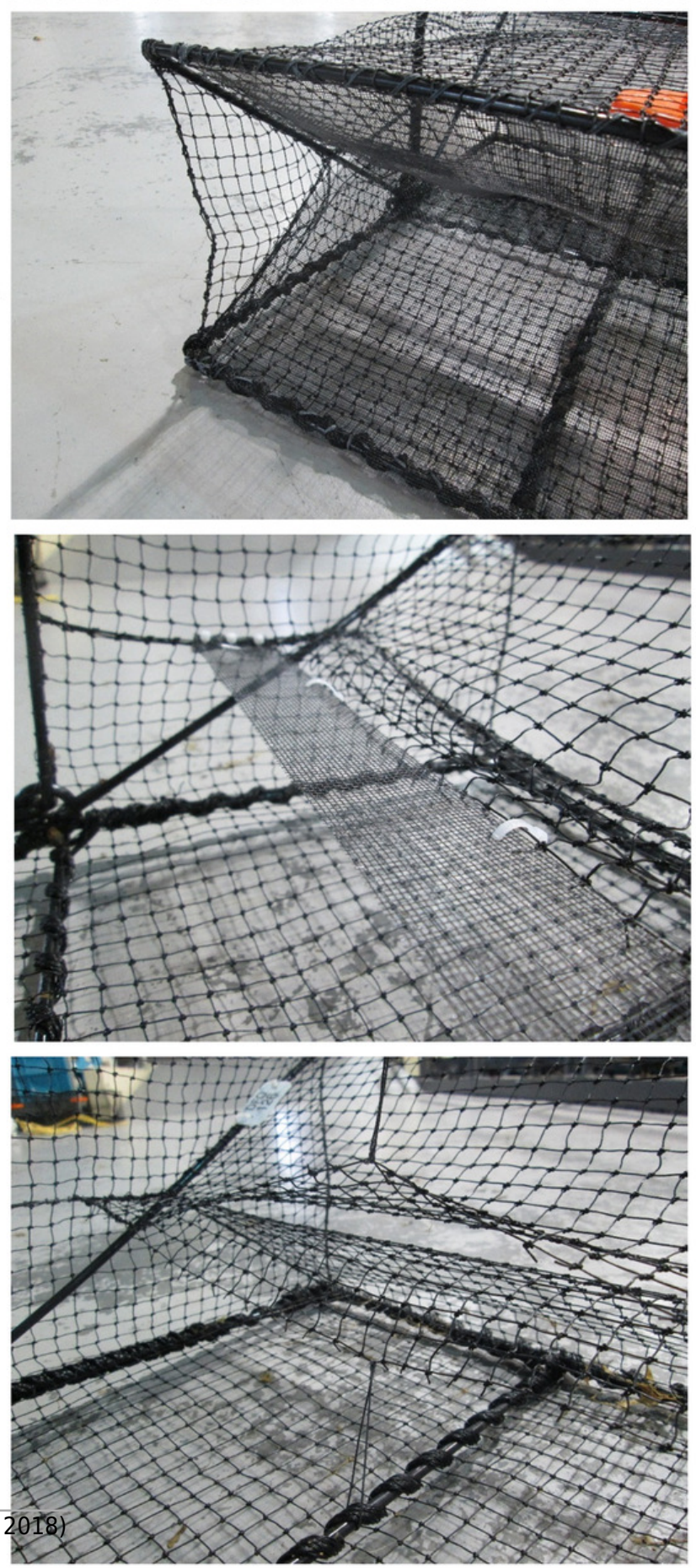


\section{Figure 2}

Maps showing the location of our study sites and experimental blocks.

Map A shows the location of North Harbour, NL and Fox Harbour, NL. The city of St. John's, NL is included for reference. Maps B and C show the location of our experimental blocks at North Harbour and Fox Harbour, respectively. We produced these maps using the ggmap package (Kahle \& Wickham, 2013) in R (R Core Team, 2015). Map A imagery (c 2018 TerraMetrics. Map B and C imagery (c) 2018 CNES/Airbus, DigitalGlobe.
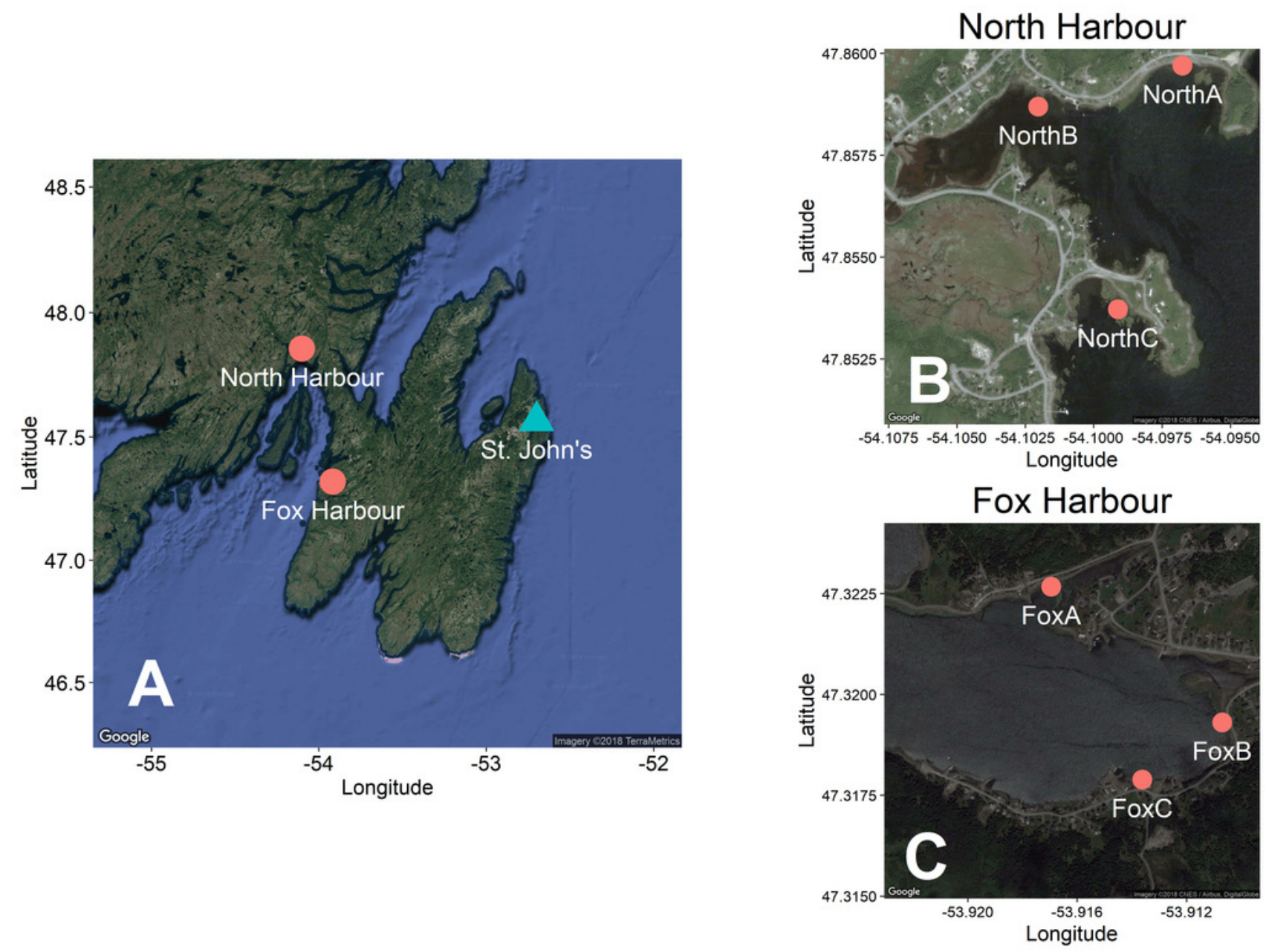


\section{Figure 3}

Boxplot illustrating the average number of green crabs captured in each trap type.

Each data point represents the number of green crabs captured for an individual trap deployment. The solid black line within each box depicts the median for that trap type. The lower and upper hinges of the box correspond to the first and third quartiles, respectively. The upper whisker extends to the largest value no further than 1.5 times the inter-quartile range $(1.5 * \mid \mathrm{QR})$, and the lower whisker extends to the smallest value no further than $1.5 * \mathrm{QQR}$. Any data points beyond these whiskers are considered outliers. Outliers above 125 are not displayed ( $n=1,1,2,2,0$ respectively).

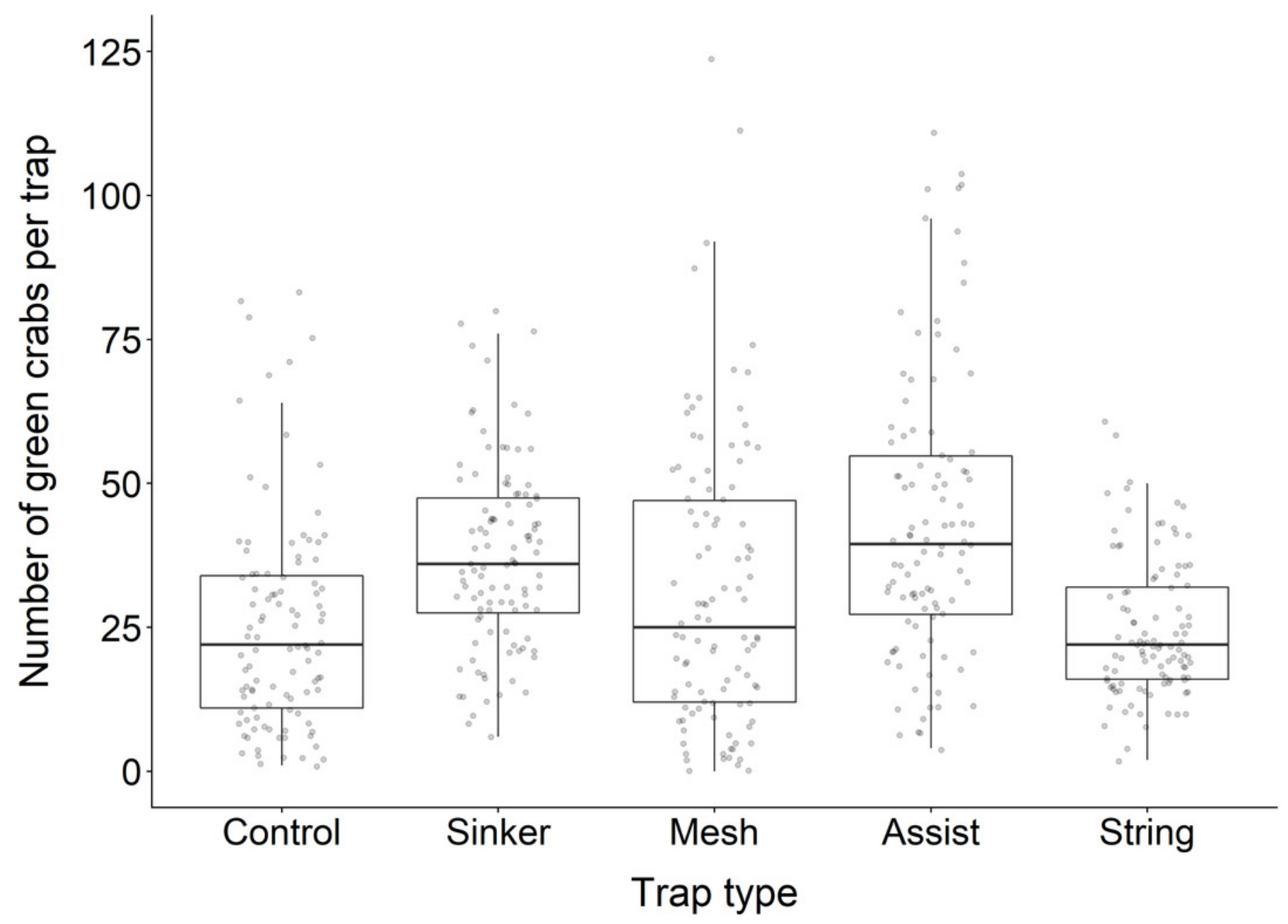




\section{Figure 4}

The mean carapace width (A) and total proportion (B) for male and female green crabs captured in each trap type.

Each data point in the boxplot (A) represents the carapace width of an individual green crab. The solid black line within each box depicts the median for that trap type. The lower and upper hinges of the box correspond to the first and third quartiles, respectively. The upper whisker extends to the largest value no further than 1.5 times the inter-quartile range (1.5*IQR), and the lower whisker extends to the smallest value no further than $1.5 *$ IQR. Any data points beyond these whiskers are considered outliers. The bar chart (B) depicts the total proportion of female and male green crabs captured for each trap type. The numerical values represent the sample size for each proportion. 


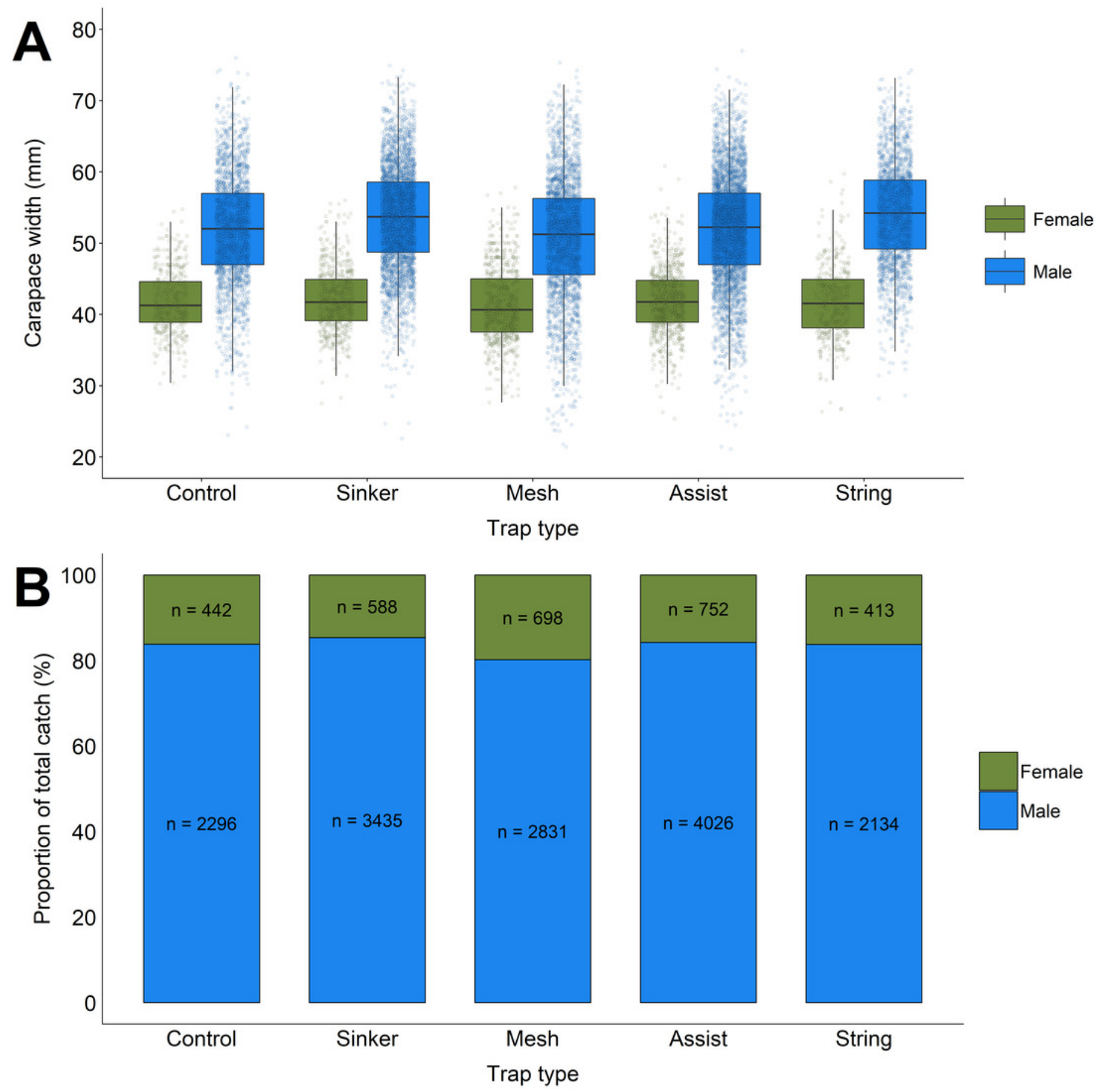




\section{Table $\mathbf{1}$ (on next page)}

Summary of trap deployments at Fox Harbour, NL and North Harbour, NL. 
Traps Replicates Deployment duration Catch per deployment Min. Max. Total green deployed $(n) \quad(n) \quad(h)($ mean \pm SD $) \quad($ mean \pm SD $) \quad$ catch catch crabs caught

\begin{tabular}{|c|c|c|c|c|c|c|c|}
\hline $\begin{array}{l}\text { Fox } \\
\text { Harbour }\end{array}$ & 390 & 78 & $24.1 \pm 2.2$ & $35.5 \pm 27.6$ & 0 & 211 & 13,855 \\
\hline $\begin{array}{l}\text { North } \\
\text { Harbour }\end{array}$ & 130 & 26 & $23.2 \pm 2.8$ & $28.9 \pm 16.8$ & 1 & 88 & 3,760 \\
\hline Overall & 520 & 104 & $23.9 \pm 2.4$ & $33.9 \pm 25.4$ & 0 & 211 & 17,615 \\
\hline
\end{tabular}




\section{Table 2 (on next page)}

Summary of all bycatch species captured in each trap type.

The number of green crabs caught in each trap type has also been included for comparison purposes. 


\begin{tabular}{llllll} 
& Control & Sinker & Mesh & Assist & String \\
\hline Rock crab (Cancer irroratus) & 18 & 42 & 26 & 38 & 33 \\
Sculpin spp. (Myoxocephalus spp.) & 1 & 1 & 1 & 0 & 1 \\
Cunner (Tautogolabrus adspersus) & 0 & 1 & 1 & 1 & 1 \\
Rock gunnel (Pholis gunnellus) & 1 & 0 & 0 & 0 & 2 \\
Atlantic cod (Gadus morhua) & 1 & 0 & 1 & 1 & 0 \\
Winter flounder (Pseudopleuronectes & 0 & 0 & 0 & 0 & 2 \\
americanus) & 1 & 0 & 0 & 0 & 0 \\
Sea trout (Salmo trutta) & 2,738 & 4,023 & 3,529 & 4,778 & 2,547
\end{tabular}




\section{Table 3 (on next page)}

Summary of green crab captured in each trap type. 


\begin{tabular}{llllll} 
Trap type & $\begin{array}{l}\text { Traps } \\
\text { deployed (n) }\end{array}$ & $\begin{array}{l}\text { Catch per deployment } \\
(\text { mean } \pm \text { SD) }\end{array}$ & $\begin{array}{l}\text { Minimum catch } \\
\text { per deployment }\end{array}$ & $\begin{array}{l}\text { Maximum catch } \\
\text { per deployment }\end{array}$ & $\begin{array}{l}\text { Total green crabs } \\
\text { captured }\end{array}$ \\
\hline Control & 104 & $26.3 \pm 22.0$ & 1 & 143 & 2,738 \\
Sinker & 104 & $38.7 \pm 20.7$ & 6 & 172 & 4,023 \\
Mesh & 104 & $33.9 \pm 30.7$ & 0 & 167 & 3,529 \\
Assist & 104 & $45.9 \pm 30.7$ & 4 & 211 & 4,778 \\
String & 104 & $24.5 \pm 12.0$ & 2 & 61 & 2,547
\end{tabular}




\section{Table 4 (on next page)}

Estimated regression parameters, standard errors, $z$ values, and $P$-values for the negative binomial generalized linear mixed-effects model (GLMM) presented in Eqn (1).

The estimated value of $\sigma_{\text {studydy }}$ is 0.368 . 


\begin{tabular}{lrrrr}
\hline & Estimate & Std. error & $z$ value & $P$-value \\
\hline Intercept & 3.456 & 0.098 & 35.120 & $<0.001$ \\
Sinker & 0.461 & 0.074 & 6.220 & $<0.001$ \\
Mesh & 0.253 & 0.075 & 3.370 & 0.001 \\
Assist & 0.593 & 0.074 & 8.030 & $<0.001$ \\
String & 0.029 & 0.075 & 0.380 & 0.705 \\
FoxB & -0.323 & 0.066 & -4.920 & $<0.001$ \\
FoxC & -0.568 & 0.067 & -8.530 & $<0.001$ \\
NorthA & -0.527 & 0.173 & -3.050 & 0.002 \\
NorthB & -0.379 & 0.169 & -2.240 & 0.025 \\
NorthC & -0.333 & 0.169 & -1.970 & 0.048 \\
\hline
\end{tabular}




\section{Table 5 (on next page)}

Estimated regression parameters, standard errors, $t$ values, and $P$-values for the linear mixed-effects model (LME) presented in Eqn (2).

The estimated value of $\sigma_{\text {studyDay }}$ is 1.223 . 


\begin{tabular}{lrrrrr}
\hline & Value & Std. error & $d f$ & $t$ value & $P$-value \\
\hline Intercept & 40.945 & 0.423 & 17549 & 96.820 & $<0.001$ \\
Sinker & 0.464 & 0.447 & 17549 & 1.039 & 0.299 \\
Mesh & -0.565 & 0.432 & 17549 & -1.308 & 0.191 \\
Assist & 0.253 & 0.426 & 17549 & 0.593 & 0.553 \\
String & -0.058 & 0.487 & 17549 & -0.119 & 0.905 \\
Male & 9.823 & 0.369 & 17549 & 26.636 & $<0.001$ \\
FoxB & 0.614 & 0.144 & 17549 & 4.273 & $<0.001$ \\
FoxC & 1.695 & 0.154 & 17549 & 11.004 & $<0.001$ \\
NorthA & 2.988 & 0.536 & 17549 & 5.580 & $<0.001$ \\
NorthB & 2.190 & 0.521 & 17549 & 4.207 & $<0.001$ \\
NorthC & 1.987 & 0.518 & 17549 & 3.833 & $<0.001$ \\
Sinker:Male & 1.213 & 0.486 & 17549 & 2.494 & 0.013 \\
Mesh:Male & -0.628 & 0.475 & 17549 & -1.322 & 0.186 \\
Assist:Male & -0.300 & 0.464 & 17549 & -0.646 & 0.518 \\
String:Male & 1.914 & 0.531 & 17549 & 3.602 & $<0.001$ \\
\hline
\end{tabular}

1 